\title{
Research Paper: Investigating Suicide Rate and Poisoning Severity and Their Relationship With Birth Month
}

\author{
Gholamali Dorooshi $^{1}$, , Shiva Samsam Shariat ${ }^{2}$, Mitra Shirvani ${ }^{3}$, Shafeajafar Zoofaghari ${ }^{*}$ (D)
}

1. Department of Clinical Toxicology, School of Medicine, Isfahan Clinical Toxicology Research Center, Isfahan University of Medical Sciences, Isfahan, Iran.

2. Department of Emergency Medicine, School of Medicine, Isfahan University of Medical Sciences, Isfahan, Iran

3. Department of General Medicine, School of Medicine, Isfahan University of Medical Sciences, Isfahan, Iran.

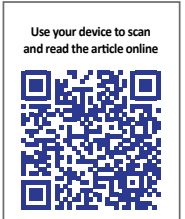

ditation: Dorooshi Gh, Samsam Shariat Sh, Shirvani M, Zoofaghari Sh. Investigating Suicide Rate and Poisoning Severity and Their Relationship With Birth Month. International Journal of Medical Toxicology and Forensic Medicine. 2019; 9(4):233242. https://doi.org/10.32598/ijmtfm.v9i4.26306

dol $\mathrm{https://doi.org/10.32598/ijmtfm.v9i4.26306}$

\section{(1) (8)}

Article info:

Received: 11 May 2019

First Revision: 25 May 2019

Accepted: 27 Aug 2019

Published: 01 Oct 2019

\section{Keywords:}

Poisoning, Suicide, Birth month, SAD PERSONS Scale (SPS)

\section{ABSTRACT}

Background: One of the most frequent causes of death is poisoning worldwide. Investigating the causes of mortality due to poisoning profoundly affects making decisions and improving standards for preventing adverse events. Therefore, to better understand this problem and evaluate the causes, this study aimed to determine the risk of suicide using the SAD PERSONS Scale (SPS) criteria and its relationship with the birth month in poisoned patients.

Methods: This cross-sectional descriptive-analytic study was conducted on poisoned patients admitted to Khorshid Hospital in Isfahan City, Iran, in 2018. First, the patients' age, gender, and birth month were recorded. Then, their suicide risk was assessed by SPS.

Results: From 2735 referred patients with poisoning, 1839 (67.2\%) attempted suicide, and $896(32.8 \%)$ cases were poisoned. The Mean \pm SD SPS score in patients with suicidal attempts was $4.89 \pm 1.94$, and in the poisoned patients was equal to $2.74 \pm 1.46(\mathrm{P}<0.001)$. There was no significant relationship between suicide and birth month; however, gender (male), age, depression, previous suicidal attempts, ethanol abuse, rational thinking loss, social support lacking, and being unmarried significantly increased the risk of suicide $(\mathrm{P}<0.01)$. In addition, the SPS scores $\geq 5$ with a sensitivity of $43.77 \%$, and specificity of $98.44 \%$ had an acceptable diagnostic value in identifying the risk of suicide $(\mathrm{P}<0.0001)$.

Conclusion: As SPS criteria have an appropriate diagnostic value for suicide prediction, it is recommended that these criteria be assessed among individuals with susceptible suicide characteristics (e.g. males, elders, depression, the lack of social support, etc.), to prevent future suicide attempts and appropriate medical-psychological measures.

\footnotetext{
* Corresponding Author:
}

Shafeajafar Zoofaghari, MD.

Address: Department of Clinical Toxicology, Isfahan Clinical Toxicology Research Center, School of Medicine, Isfahan University of Medical Sciences, Isfahan, Iran.

Tel: +98 (913) 1146218

E-mail: shafeajafarzoofaghari@yahoo.com 


\section{Introduction}

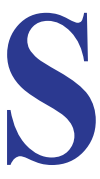

uicide is among the most important international public health problems, leading to a death per 40 seconds [1]. It is the second leading cause of death in people aged 15 to 29 years and is responsible for 39 million years of life with disability in 2012 [2]. On average, the suicide rate is around 11.4 per 100000 people worldwide [1]. Suicide is also a growing phenomenon in Iran, with a rate of 5.3 per 100000 individuals in 2014 [3, 4].

Furthermore, $54 \%$ of suicides leading to deaths occurred among people $<30$ years of age, and it has been twice in men than in women [5]. With each suicide, at least 6 close relatives and friends become inconsolable, and depression and suicide risks also increase in these individuals [6-8]. The economic cost of suicide and selfharm is significant, with an average annual (direct and indirect) cost of $\$ 41$ billion in the United States [9]. Accordingly, identifying suicide-related factors as well as those at risk of suicide and interventions to reduce suicide in potential groups are the priority of national research programs and government strategies for suicide prevention [10].

In this regard, factors such as psychiatric disorders, misuse of drugs, personality traits, substance abuse, cultural, family, and socioeconomic conditions (unemployment, poverty, the lack of housing and discrimination in society), and genetics are among the factors influencing suicide risk. Other risk factors include previously attempted suicide, availability of the instruments to commit suicide, family history of suicide, or brain damage $[11,12]$.

A frequent strategy to develop a suicidal risk assessment scale is to collect potential risk factors for suicide based on the concepts of the face or content validity. Hazard scales that are often studied include Beck Hopelessness Scale (BHS), Beck Depression Inventory (BDI), Beck Scale for Suicidal Ideation (BSS), Beck's Suicide Intent Scale (SIS), and SAD PERSONS Scale (SPS) [13-16].

SPS is the most prevalently used suicide risk assessment scale [16]. This scale is stronger in predicting suicide within $<6$ months and is generally more suitable for people without psychiatric admissions, psychiatric follow-ups, or a history of self-harm. In systematic reviews, no adequate evidence has been found to support its use in predicting suicide risk [17]. Only two studies have examined the power of this scale to predict suicide risk. Its sensitivity and positive predictive value were estimated to be $23 \%$ and $5 \%$, respectively $[18,19]$.

Recently, some researchers have investigated the suicide rate in different seasons of the year and various birthdays; they explored significant relationships in this respect. Moreover, the effects of season and month of birth have been reported on several diseases. The effect of the birth season has been reported on acute lymphoblastic leukemia in children, non-Hodgkin's lymphoma, breast cancer, testicular cancer, Crohn's disease, cardiovascular diseases, and brain tumors [20, 21]. Few studies have examined the effects of month and season of birth on suicidal attempts and have concluded that suicide occurred highest in July or Summer [22, 23].

The suicide rate in patients in different parts of hospitals, especially the poisoning ward, is increasing. Moreover, the nature of this action and its associated risks are significant. In addition, there is a lack of a recent study on effective factors on suicide as well as the month of birth and its relation to suicide. Thus, it is necessary to identify the relationship between the risk of suicidal attempts and month of birth in hospitalized patients, especially in the poisoning ward. Accordingly, the present study aimed to determine the risk of suicide (using the SPS) and its relationship with the month of birth in patients admitted to the poisoning department of Khorshid Hospital in Isfahan City, Iran, in 2018.

\section{Materials and Methods}

This was a cross-sectional study. The study population consisted of all patients admitted to the poisoning department in Khorshid Hospital in Isfahan City, Iran, in 2018. We applied the census sampling technique to select the study samples. The patients were excluded from the study if having another chronic illness, along with poisoning or the lack of cooperation or consent to participate in the study.

After receiving the ethics code from the Ethics Committee of Isfahan University of Medical Sciences as well as written consent from patients or their hospital attendant, a total of 2735 patients were enrolled in the study. Initially, age, gender, and month of birth, and the method of suicide or poisoning were recorded. The SPS was then used to assess the suicidal risk.

This scale was first used by Patterson et al. as a clinical evaluation tool for physicians to determine the suicide risk [16]. This scale was then developed by Juhnke for 
use in children in 1996 [24]. Recent studies indicated that this scale has high specificity and very low sensitivity [4].

SPS consists of 10 yes/no questions; each positive answer is assigned a score. S: male gender, A: age ( $<19$ or $>45$ years), D: depression, P: previous suicide attempt, E: the excessive consumption of alcohol or substances, $\mathrm{R}$ : rational thinking loss, S: the lack of social support, $\mathrm{O}$ : existence of an organized program for suicide, N: no spouse, and S: the sources of underlying illness. The total score obtained on this scale evaluates the suicide risk, where the scores 0-4 indicate low risk of suicide, scores 5-6: average risk of suicide, and scores 7-10 reflect a high risk of suicide.

Independent Samples t-test was used to compare the mean SPS score among patients with poisoning and suicide, using logistic regression using Odds ratio to determine the factors affecting the risk of suicide based on SPS scale. Additionally, Kendall's correlation coefficient was used to compare the relationship between
SPS scores and patient's month of birth, and eventually, ROC analysis was used to identify the cut-off point of increased suicide risk. In all analyses, the significance level was considered to be $<0.05$. The obtained data were analyzed in SPSS.

\section{Results}

A total of 2735 patients admitted to the poisoning department in Khorshid Hospital of Isfahan City, Iran, in 2018 , with the Mean \pm SD age of $29.83 \pm 11.85$ years, of whom $1839(67.2 \%)$ committed suicide and $896(32.8 \%)$ were poisoned, were the statistical population of this study. Patients $<10$ years old were all poisoned, and the average age of the poisoned patients was significantly lower than those who attempted suicide. In addition, of the patients who had committed suicide, $58.5 \%$ were female, and $41.5 \%$ were male. A significant frequency of these patients was also poisoned due to drug misuse (excessive use) or household detergent consumption, while

Table 1. The demographic data of study participants

\begin{tabular}{|c|c|c|c|c|}
\hline \multirow{2}{*}{\multicolumn{2}{|c|}{ Characteristics }} & \multicolumn{3}{|c|}{ No. (\%) } \\
\hline & & \multirow{2}{*}{$\begin{array}{c}\text { Total }(\mathbf{N}=\mathbf{2 7 3 5}) \\
29.83 \pm 11.85\end{array}$} & \multirow{2}{*}{$\begin{array}{c}\text { Suicide }(\mathbf{n}=\mathbf{1 8 3 9}) \\
30.37 \pm 12.09\end{array}$} & \multirow{2}{*}{$\begin{array}{c}\text { Poisoning }(\mathbf{n}=\mathbf{8 9 6}) \\
28.74 \pm 11.29\end{array}$} \\
\hline & Mean $\pm S D$ & & & \\
\hline & $<10$ & $14(0.5)$ & $0(0.0)$ & $14(1.6)$ \\
\hline & $10-15$ & $112(4.1)$ & $79(4.3)$ & $33(3.7)$ \\
\hline & $15-20$ & $514(18.8)$ & $360(19.6)$ & 154 (17.2) \\
\hline \multirow[t]{5}{*}{ Age, (y) } & $20-25$ & $503(18.4)$ & 277 (15.1) & $226(25.2)$ \\
\hline & $25-30$ & $491(18.0)$ & 347 (18.9) & $144(16.1)$ \\
\hline & $30-35$ & 385 (14.1) & $268(14.6)$ & 117 (13.1) \\
\hline & $35-40$ & $283(10.3)$ & 213 (11.6) & $70(7.8)$ \\
\hline & $>40$ & 433 (15.8) & $295(16.0)$ & 138 (15.4) \\
\hline \multirow{2}{*}{ Gender } & Female & 1714 (62.7) & $1076(58.5)$ & $638(71.2)$ \\
\hline & Male & 1021 (37.3) & 763 (41.5) & $258(28.8)$ \\
\hline \multirow{5}{*}{$\begin{array}{l}\text { Method of } \\
\text { poisoning/ suicide }\end{array}$} & Drugs & 2361 (86.3) & $1589(86.4)$ & 772 (86.2) \\
\hline & Narcotics & $149(5.4)$ & $88(4.8)$ & $10(1.1)$ \\
\hline & Detergents & $31(1.1)$ & $21(1.1)$ & $61(6.8)$ \\
\hline & Poisons & $186(6.8)$ & $136(7.4)$ & $50(5.6)$ \\
\hline & Unknown & $8(0.3)$ & $5(0.3)$ & $3(0.3)$ \\
\hline
\end{tabular}




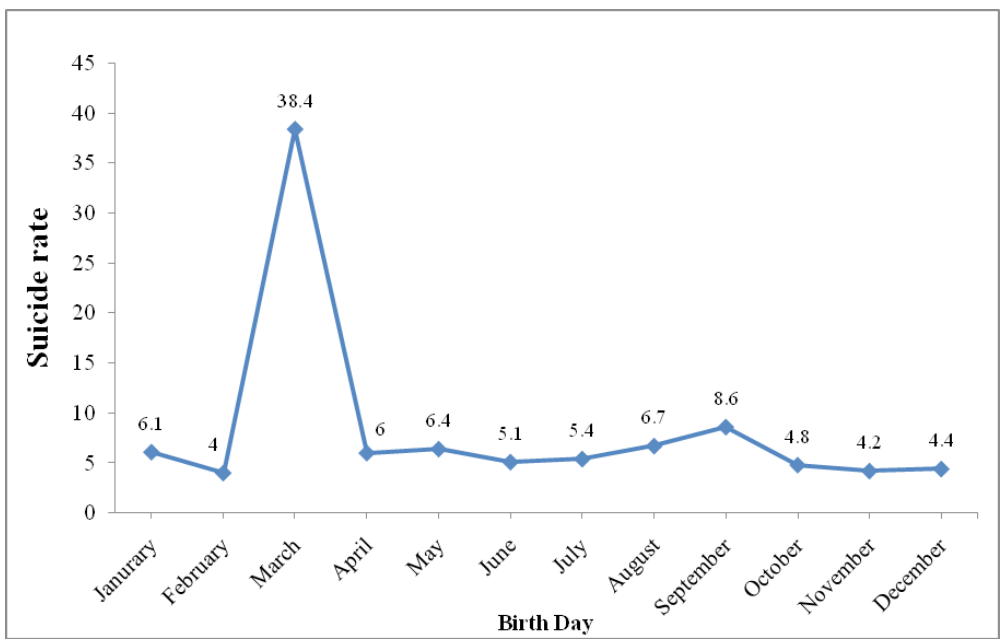

Figure 1. Frequency of suicide rate by the month of birth

the highest frequency of suicidal patients used domestic and agricultural agents (Table 1).

Furthermore, the highest frequency of suicide rates in the patients whose month of birth was March was $38.4 \%$, and the lowest incidence was in February with $4 \%$ (Figure 1).

In addition, the Mean \pm SD SPS score of patients who committed suicide was $4.89 \pm 1.94$, and in patients with poisoning, it was $2.74 \pm 1.46(\mathrm{P}<0.001)$. Moreover, evaluating factors influencing suicide by SPS using logistic regression indicated that male gender, age (25-34; 35-44; $65+$ years), depression, previous attempts, ethanol abuse, rational thinking loss, social support lacking, and being single have significantly increased suicide risk $(\mathrm{P}<0.01)$; the most effective factors were the risk of committing suicide with depression and previous suicide attempts of $62.364 \%$ and $25.550 \%$, respectively $(\mathrm{P}<0.001)$.

Table 2. Evaluating effective factors on suicide risk factor based on SPS

\begin{tabular}{cccc}
\hline Variables & OR & 95\% Cl & P \\
\hline Sex & 1.512 & $1.126-2.029$ & 0.006 \\
\hline Age, (y) & 22.695 & $13.876-37.119$ & $<0.001$ \\
\hline Depression & 62.364 & $57.124-111.735$ & $<0.001$ \\
\hline Previous attempts & 25.550 & $11.513-56.703$ & $<0.001$ \\
\hline Ethanol abuse & 2.256 & $1.734-4.488$ & $<0.001$ \\
\hline Rational thinking loss & 0.520 & $0.379-0.714$ & $<0.001$ \\
\hline Social support lacking & 2.396 & $1.723-3.333$ & $<0.001$ \\
\hline Organized plan & 1.142 & $0.835-1.562$ & $0.406^{*}$ \\
\hline No spouse & 1.530 & $1.067-2.194$ & 0.021 \\
\hline Sickness & 1.105 & $0.786-1.552$ & $0.566^{*}$ \\
\hline
\end{tabular}

Sex ( 1 if patient is male; 0 if female), Age 1 if patient is $(25-34 ; 35-44 ; 65+$ years), Depression (yes=1, no= 0$)$, Previous attempt $(1$ if present; 0 otherwise), Ethanol abuse ( 1 if present; 0 otherwise), Rational thinking loss ( 1 if patient is psychotic for any reason: schizophrenia, affective illness, organic brain syndrome; 0 otherwise), Social support lacking ( 1 if these are lacking it, especially with the recent loss of a significant other; 0 otherwise), Organized suicidal plan ( 1 if plan made and method lethal; 0 if no plan), No spouse ( 1 if divorced, widowed, separated, or single - for males only), Sickness ( 1 especially if chronic, debilitating, severe: e.g. non-localized cancer, AIDS, MS, gastrointestinal disorders; 0 if nothing reported).

* This factor had no significant effect on suicide risk 


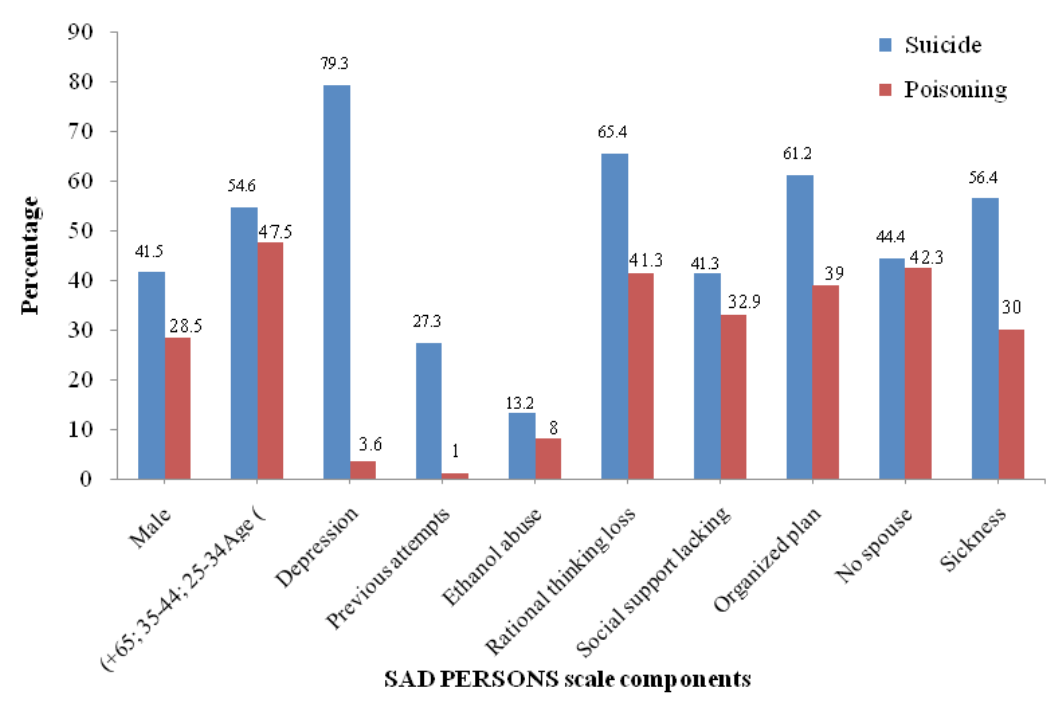

Figure 2. Frequency of SPS factors in patients with poisoning and suicide

In contrast, two factors of organized suicidal plan and sickness had no significant effect on suicidal risk $(\mathrm{P}>0.05)$ (Table 2, Figure 2).

There was a poor relationship between the score obtained from the SPS and the month of birth of the patients who committed suicide. Thus, the month of birth of individuals is ineffective on the increased SPS score (Kendall's correlation $=0.011 ; \mathrm{P}=0.458$ ) (Figure 3).

There was no significant relationship between the birth month and suicide. Moreover, some SPS factors played no significant role in increasing suicide risk. Therefore, ROC analysis (to determine the cut-off point of this scale) was used to identify the potential risk of suicide; the obtained results suggested that patients with the SPS $\geq 5$ with a sensitivity of $43.77 \%$ and a specificity of $98.44 \%$ and positive predictive value of $98.3 \%$ power risk identification have committed suicide. However, removing two unrelated factors from this scale indicated that in the Modified SAD PERSONS Scale (MSPS), scores $\geq 3$, with a sensitivity and specificity of $55.64 \%$ and $73.93 \%$, respectively had an acceptable diagnostic value in identifying the suicide risk $(\mathrm{P}<0.0001)$ (Table 3 ).

\section{Discussion}

The study results revealed that $67.2 \%$ of the patients hospitalized in the poisoning ward in 2018 intentionally committed suicide and $32.8 \%$ of them were poisoned unintentionally. The frequency of female to male poisoning was $62.7 \%$ to $37.3 \%$, and the Mean $\pm \mathrm{SD}$ age of patients who committed suicide was $30.37 \pm 12.09$ years; the same rate in patients with unintentional poisoning was $28.74 \pm 11.29$ years. All patients aged $<10$ suffered from unintended poisoning, and most of these unconsciously poisoned patients have been poisoned due to the use of household products and household detergents, or misuse or excessive use of drugs. However, suicide attempters had often used drugs and poisons for suicide.

Another study investigated the causes and majority of poisoning in 7000 patients hospitalized in the poisoning department of Loghman Hakim Hospital in Tehran. They concluded that $87.5 \%$ of the cases were related to suicide (intentional poisoning). The overall ratio of females to males was 1: 1.8, with the highest age range of 2-4 years in children and 21-40 years in adults. Oral consumption was the most prevalent method of poison-

Table 3. ROC analysis to identify risk factors of suicide based on SAD PERSONS Scale (SPS)

\begin{tabular}{cccccccc}
\hline Scale & Cut-off score & Sensitivity & Specificity & PPV & NPV & AUC & P \\
\hline SAD PERSONS Scale & $\geq 5$ & 43.77 & 98.44 & 98.3 & 46.0 & 0.806 & $<0.0001$ \\
Modified SPS* & $\geq 3$ & 55.64 & 73.93 & 57.3 & 72.6 & 0.750 & $<0.0001$ \\
\hline * In the Modified SPS removed two items ("Organized plan" and "Sickness") & & $\begin{array}{l}\text { International Journal of } \\
\text { Medical Toxicology E Forensic Medicin }\end{array}$
\end{tabular}




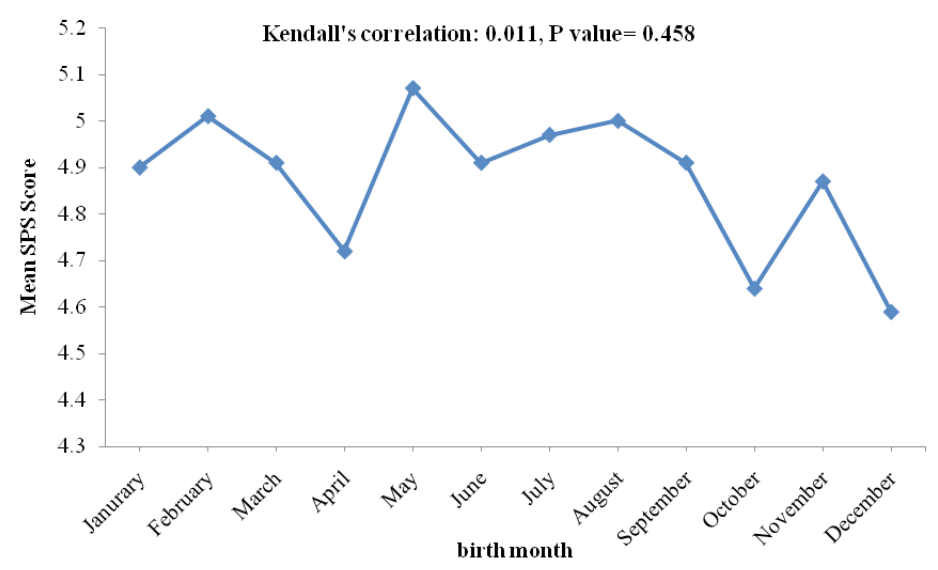
International Journal of
Medical Toxicology \& forensic Medicine

Figure 3. The average SPS based on the month of birth in patients with suicidal attempts

ing. Additionally, in adults, the most common cause of poisoning was drug use (60.2\%) [25].

Srivastava et al. reported the most common reasons for poisoning were suicide (53\%), then accidental (unintended) poisoning (47\%) [26]. Moreover, some studies indicated that the majority of unintended poisoning has mainly occurred among children; in our study, $0.5 \%$ of children aged $<10$ years were unintentionally poisoned. The leading cause of children's poisoning in the study by Presgrave et al. was the use of household detergents for consumer products. However, children aged $<5$, as well as boys $<10$ (compared to girls), were the most vulnerable group in this regard. The most commonly used products included bleachers, petroleum derivatives, multivitamins, and pesticides [27].

Poisoning due to the use of detergents, household products, and chemicals have also been reported in several studies [26, 28-30]. The leading cause of this poisoning in all of these studies is the storage of these products in the bottles of beverages, mixing these materials with foods, and the misuse of these products in kitchen utensils.

The most important consideration of the previous researchers and the main attention of this study was to find a standard for the early prediction of this event and its prevention. Researchers were looking for criteria that can help identify those susceptible to such unpleasant actions and treat them before taking any dangerous action.

One of Such criteria that has recently been taken into consideration by researchers is the SPS scale. In this study, according to this scale, those who committed suicide had a higher score than those with unintended poisoning. In addition, among the 10 measured items, 8 items (gender, age: 25-34, 35-44; 65+, depression, pre- vious suicide attempts, ethanol abuse, rational thinking loss, social support lacking, and being single) had a significant impact on the increased suicide risk. In addition, the cut-off point obtained on the basis of the SPS scale was $\geq 5$, with a sensitivity and specificity of $43.77 \%$ and $98.44 \%$, respectively. After the scale was modified, and two irrelevant items were eliminated, and the scale was changed to a set of 8 items (MSPS), the cut-off point obtained from this scale (MSPS) was $\geq 3$ points with a sensitivity and specificity of $55.64 \%$ and $73.93 \%$, respectively. By modifying this scale, its sensitivity increased and its specificity reduced; however, it seems that further research is required in this area.

Warden et al. (2014) conducted the first systematic review study on SPS risk assessment for suicide risk. Of 149 studies, only 9 met the study inclusion criteria and had a high sample size to accurately assess the clinical status of patients. Of these 9 studies, 3 evaluated SPS performance investigations in suicide prediction, suggesting that this scale fails to accurately predict suicidal behavior. Furthermore, it was argued that the main problem in evaluating this research was a minimal database for SPS and the poor quality of available articles [17].

in this respect, many other researchers evaluated the diagnostic value of this scale in identifying the suicide risk in different populations worldwide. For example, in the Western European population, $a \geq 5$ rating was recommended as the cut-off of this scale. They also used cut-off points 3 or 4 in comparing low-risk patients with high-risk patients [18].

Additionally, in the American population, the cut-off point of this score was $>5$, with high false positives [31]. Therefore, the researchers strived to modify this scale according to their populations and sought a more 
precise scale with higher sensitivity and higher predictive power. In this regard, numerous studies have been conducted with six-month and one-year follow-ups of patients who have been referred to hospitals with intentional poisoning or self-harm. Modifying this scale (expressing it as MSPS) indicated that attempts to committing suicide within 6 months or one year were more frequent in patients with an MSPS score of $>5$ [32]. In addition, other studies stated the cut-off points obtained from this modified scale equal to $>6$, with a sensitivity and specificity of $100 \%$ and $68.5 \%$ [33], and scores of $>9$ with a sensitivity of $31.3 \%$ and a specificity of $94.4 \%$ [17]. However, these studies have been inconsistent in terms of applying a single scale, and they all have suggested further research.

According to recent theories about the potential relationship between birth month and suicide, this study also evaluated this relationship; we observed a poor relationship between birth month and suicide attempt. Furthermore, March produced the highest frequency of suicide rates, whereas there were the fewest suicide attempts in February.

In addition, some studies have argued that the distribution of birth month for suicide-induced deaths was different from those who did not commit suicide [22]. Other studies also found that the highest rates of suicide were in those who were born in July and in Summer [21-23].

Moreover, Salib et al. stated that males born in the Spring who committed suicide used violent methods, and non-violent methods were at peak in the Summer. Furthermore, the lowest rate for both methods occurred in Autumn. Regarding females, the highest values were in the late-Spring born ones, and the lowest rates belonged to Autumn for both methods [22].

\section{5. conclusion}

The majority of studies conducted in this regard date back to many years ago; the issue has recently been less paid attention to. However, month or season of birth impacts the incidence of some diseases, in particular psychiatric disorders, such as schizophrenia, Alzheimer's disease, epilepsy, narcolepsy (mostly in December and January), emotional disturbances, alcohol dependence, autism, dyslexia, and multiple sclerosis (mostly in the Spring and Summer months) [20, 22]. Therefore, paying attention to birth month as a contributor to the associated factors of increased SPS score and consequently the increased risk of suicide is beneficial. In addition to extending the knowledge boundaries, special care should be given to the people born in some months and pay attention to their mental health.

A limitation of this study was the lack of follow-up of suicide attempts in the studied patients. In addition, the fates of these patients were also not recorded, and we had no information on the survival or death of these patients following a suicide. Therefore, it is suggested that in future studies, patients be monitored for at least 6 months and the outcome of the suicide (successful or unsuccessful) also be evaluated. Moreover, the odds of suicide risk should be measured by this scale. Furthermore, due to the dearth of such a study in Iran, the investigated data provided a substantial opportunity to assess the suicide risk; further studies are necessary with a larger sample size in this area.

\section{Ethical Considerations}

\section{Compliance with ethical guidelines}

All procedures involving the human participant were in accordance with the ethical standards of the institutional and or national research committee, the 1964 Helsinki Declaration, and its later amendments or comparable ethical standards. Private information, including name, surname, and burial permit was removed from the data sheet to comply with ethical concerns.

\section{Funding}

This research did not receive any specific grant from funding agencies in the public, commercial, or not-forprofit sectors.

\section{Author's contributions}

Patient care, data acquisition, literature review, drafting and submitting the manuscript: Shafeajafar Zoofaghari, Gholmali Dorooshi; Critically reviewed the draft for important intellectual content: Shafeajafar Zoofaghari; Revised it for english style and language: Shafeajafar Zoofaghari; Reviewed and approved the final and submitted version of the manuscript: All authors.

\section{Conflict of interest}

The authors declare no conflict of interest.

\section{Acknowledgements}

We would like to thank Toxicology Department Personnel for their encouragement through this work. 


\section{References}

[1] World Health Organization. Preventing suicide-a global imperative. Geneva: World Health Organization; 2014

[2] World Health Organization. Global Health Estimates. Geneva: World Health Organization; 2014.

[3] Hassanian-Moghaddam H, Zamani N. Suicide in Iran: The facts and the figures from nationwide reports. Iranian Journal of Psychiatry. 2017; 12(1):73-7. [PMID] [PMCID]

[4] Katz C, Randall JR, Sareen J, Chateau D, Walld R, Leslie WD, et al. Predicting suicide with the SAD PERSONS scale Depression and Anxiety. 2017; 34(9):809-16. [DOI:10.1002/ da.22632] [PMID]

[5] Sharif-Alhoseini M, Rasouli MR, Saadat S, Haddadi M, Gooya MM, Afsari M, et al. Suicide attempts and suicide in Iran: results of national hospital surveillance data. Public Health. 2012; 126(11):990-2. [DOI:10.1016/j.puhe.2012.06.006] [PMID]

[6] Berman AL. Estimating the population of survivors of suicide: seeking an evidence base. Suicide and Life-Threatening Behavior. 2011; 41(1):110-6. [DOI:10.1111/j.1943278X.2010.00009.x] [PMID]

[7] Bolton JM, Au W, Leslie WD, Martens PJ, Enns MW, Roos LL, et al. Parents bereaved by offspring suicide: A population-based longitudinal case-control study. JAMA Psychiatry. 2013; 70(2):158-67. [DOI:10.1001/jamapsychiatry.2013.275] [PMID]

[8] Rostila M, Saarela J, Kawachi I. Suicide following the death of a sibling: A nationwide follow-up study from Sweden. BMJ Open. 2013; 3(4):e002618. [DOI:10.1136/bmjopen-2013-002618] [PMID] [PMCID]

[9] Office of the Surgeon General, National Action Alliance for Suicide Prevention. 2012 national strategy for suicide prevention: Goals and objectives for action: A report of the US Surgeon General and of the National Action Alliance for Suicide Prevention. Washington: US Department of Health \& Human Services; 2012.

[10] Bolton JM, Gunnell D, Turecki G. Suicide risk assessment and intervention in people with mental illness. British Journal of Medical Education. 2015; 351:h4978. [DOI:10.1136/bmj. h4978] [PMID]

[11] Mann JJ, Apter A, Bertolote J, Beautrais A, Currier D, Haas A, et al. Suicide prevention strategies: A systematic review. The Journal of the American Medical Association. 2005 294(16):2064-74. [DOI:10.1001/jama.294.16.2064] [PMID]

[12] Hawton K, van Heeringen K. Suicide. Lancet. 2009; 373(9672):1372-81. [DOI:10.1016/S0140-6736(09)60372-X]

[13] Kovacs M, Garrison B. Hopelessness and eventual suicide: A 10-year prospective study of patients hospitalized with suicidal ideation. American Journal of Psychiatry. 1985; 1(42):559-63. [DOI:10.1176/ajp.142.5.559] [PMID]

[14] Brown GK, Beck AT, Steer RA, Grisham JR. Risk factors for suicide in psychiatric outpatients: A 20-year prospective study. Journal of Consulting and Clinical Psychology. 2000; 68(3):371-7. [DOI:10.1037/0022-006X.68.3.371]
[15] Niméus A, én M, Träskman-Bendz L. High suicidal intent scores indicate future suicide. Archives of Suicide Research. 2002; 6(3):211-9. [DOI:10.1080/13811110214142]

[16] Patterson WM, Dohn HH, Bird J, Patterson GA. Evaluation of suicidal patients: The SAD PERSONS scale. Psychosomatics. 1983; 24(4):343-9. [DOI:10.1016/S0033-3182(83)73213-5]

[17] Warden S, Spiwak R, Sareen J, Bolton JM. The SAD PERSONS scale for suicide risk assessment: A systematic review. Archives of Suicide Research. 2014; 18(4):313-26. [DOI:10.1080 /13811118.2013.824829] [PMID]

[18] Kurz A, Möller HJ, Torhorst A, Lauter H. Validation of six risk scales for suicide attempters. Berlin: Springer; 1988. [DOI:10.1007/978-3-642-73358-1_25]

[19] Bolton JM, Spiwak R, Sareen J. Predicting suicide attempts with the SAD PERSONS scale: A longitudinal analysis. The Journal of Clinical Psychiatry. 2012; 73(6):3-735-41. [DOI:10.4088/JCP.11m07362] [PMID]

[20] Castrogiovanni P, Iapichino S, Pacchierotti C, Pieraccini F. Season of birth in panic disorder. Neuropsychobiology. 1999; 40(4):177-82. [DOI:10.1159/000026616] [PMID]

[21] Kettl PA, Collins T, Sredy M, Bixler EO. Seasonal differences in suicide birth rate in Alaska natives compared to other populations. American Indian and Alaska Native Mental Health Research. 1997; 8(1):1-0. [DOI:10.5820/ aian.0801.1997.1] [PMID]

[22] Salib E, Cortina-Borja M. Effect of month of birth on the risk of suicide. The British Journal of Psychiatry. 2006; 188(5):416-22. [DOI:10.1192/bjp.bp.105.009118] [PMID]

[23] Åsberg M. Neurotransmitters and suicidal behavior. Annals of the New York Academy of Sciences. 1997; 836(1):158-81. [DOI:10.1111/j.1749-6632.1997.tb52359.x] [PMID]

[24] Juhnke GA. The adapted-SAD PERSONS: A suicide assessment scale designed for use with children. Elementary School Guidance \& Counseling. 1996; 30(4):252-8.

[25] Abdollahi M, Jalali N, Sabzevari O, Hoseini R, Ghanea T. A restrospective study of poisoning in Tehran. Journal of Toxicology: Clinical Toxicology. 1997; 35(4):387-93. [DOI:10.3109/15563659709043371] [PMID]

[26] Srivastava A, Peshin SS, Kaleekal T, Gupta SK. An epidemiological study of poisoning cases reported to the national poisons information centre, All India Institute of Medical Sciences, New Delhi. Human \& Experimental Toxicology. 2005; 24(6):279-85. [DOI:10.1191/0960327105ht527oa] [PMID]

[27] Presgrave RD, Camacho LA, Villas Boas MH. A profile of unintentional poisoning caused by household cleaning products, disinfectants and pesticides. Cadernos de Saudepublica. 2008; 24(12):2901-8. [DOI:10.1590/S0102-311X2008001200019] [PMID]

[28] Williams H, Moyns E, Bateman DN, Thomas SH, Thompson JP, Vale JA. Hazard of household cleaning products: a study undertaken by the UK National Poisons Information Service. Clinical Toxicology. 2012; 50(8):770-5. [DOI:10.3109/ 15563650.2012.709937] [PMID]

[29] Bronstein, Alvin C, Daniel A. Spyker, Louis R. Cantilena Jr, Barry H. Rumack, and Richard C. Dart. 2011 annual report of the American Association of Poison Control Centers' Na- 
tional Poison data system (NPDS): 29th annual report. 2012; 50(10): 911-64. [DOI:10.3109/15563650.2012.746424] [PMID]

[30] Peshin SS, Gupta YK. Poisoning due to household products: A ten years retrospective analysis of telephone calls to the National Poisons Information Centre, All India Institute of Medical Sciences, New Delhi, India. Journal of Forensic and Legal Medicine. 2018; 58:205-11. [DOI:10.1016/j. jflm.2018.07.005] [PMID]

[31] Herman SM. Is the SADPERSONS scale accurate for the veterans affairs population? Psychological Services. 2006; 3(2):137-141. [DOI:10.1037/1541-1559.3.2.137]

[32] Kripalani M, Nag S, Nag S, Gash A. Integrated care pathway for self-harm: Our way forward. Emergency Medicine Journal. 2010; 27(7):544-6. [DOI:10.1136/emj.2009.074054] [PMID]

[33] Hockberger RS, Rothstein RJ. Assessment of suicide potential by nonpsychiatrists using the SAD PERSONS score. Journal of Emergency Medicine. 1988; 6(2):99-107. [DOI:10.1016/0736-4679(88)90147-3] 
This Page Intentionally Left Blank 